ISSN: 2362-1303 (Paper) | eISSN: 2362-1311 (Online)

JOURNAL OF ADVANCED ACADEMIC RESEARCH (JAAR)

June 2021

\title{
Care Perception of Postnatal Mother on Care during Labour in Tertiary Level Hospital, Nepal
}

\section{Saraswoti Kumari Gautam Bhattarai ${ }^{1,2}$, Kamala Dhakal ${ }^{2}$, Apsara Pandey ${ }^{2}$ and Kanchan Gautam $^{3}$}

${ }^{1}$ Karnali Academy of Health Science, Jumla

${ }^{2}$ Maharajgunj Nursing Campus, Institute of Medicine, Tribhuwan University, Kathmandu, ${ }^{3}$ Hospital for Advanced Medicine \& Surgery (HAMS), Kathmandu

\section{Corresponding Author}

Saraswoti Kumari Gautam Bhattarai

Email: saraswotigautam@gmail.com

\begin{abstract}
Background: Labour and delivery experience is one of the most significant events in a woman's life Support in labour has an impact on the childbirth experience and childbirth outcomes. A positive childbirth experience can help in mastering the major change in life. Therefore, the objective of this study was to find out postnatal mothers' perception on care during labour.

Methods: A descriptive cross-sectional design was used to explore the perception on care during labour of postnatal mothers in postnatal ward Tribhuvan University Teaching Hospital. Total 294 postnatal mothers with normal delivery were selected by purposive sampling method after receiving ethical approval from research department of Institute of Medicine and concerned authority. Data was analyzed by using descriptive as well as inferential statistics.

Results: Among 294 women; 208(70.75\%) were received care on infection prevention, $160(54.42 \%)$ received bladder care, $175(59.66 \%)$ received care on hydration maintenance, $149(50.57 \%)$ received care on injury prevention, $103(34.88 \%)$ care on comfort measures, $180(61.14 \%)$ care on information, 207(70.54\%) care on emotional support, and 201(68.31\%) care immediately after childbirth. There is significant relationship among different types of care during labour (such as emotional support (44.44\%), infection prevention care (19.7\%), care for bladder empty (14.5\%), maintenance of hydration $(17.1 \%)$, care for prevention of injury (31.9\%), care on pain relieve and comfort measures $(50.1 \%)$, informational care $(64.5 \%)$, and care immediately after delivery $(18.5 \%)$ ) and overall perception on care during labour. The perception level was based on mean score and was categorized as; below 3 is negative perception, 3 and above is positive perception. The finding of this study shows that 93(31.6\%) postnatal mothers were perceived care negatively and 201(68.4\%) perceived care positively during labour. It indicates that care during labour needs to be improved for best care perception.
\end{abstract}


ISSN: 2362-1303 (Paper) | eISSN: 2362-1311 (Online)

JOURNAL OF ADVANCED ACADEMIC RESEARCH (JAAR)

June 2021

Conclusions: Women expect professional, supportive and respectful care during labour. Continuous care and support during labour has meaningful benefits for women and infants. It indicates that the care during labour need to be improved for best care perception.

\section{KEYWORDS}

Care during labour, Care perception, Postnatal Mother.

\section{INTRODUCTION}

Labour and delivery process is an exciting, anxiety-provoking, but rewarding time for a woman and her family; and mothers expect more care. Women's perception of care is important which contributes to women's satisfaction with maternal services (Afaya et al., 2017). The health providers' attitudes care and support gave positive and negative birth experiences. Physical and psychosocial support provide comfort, relief and encouragement to the mothers while inappropriate care, poor communication and compromised privacy contributed to the mothers' negative childbirth experiences (Namujju et al., 2018). Women's perceptions about continuous support during childbirth are influenced by the characteristics and attributes of the support person as well as the types of supportive care rendered (Lunda, Minnie, \& Benadé, 2018). Disrespect and abuse is a serious obstacle to utilize the maternal health services. Facility related issues include women's perception of incompetence of professionals attending delivery, unhygienic facilities, and unavailability of basic supplies(Gebremichael, Worku, Medhanyie, \& Edin, 2018). Positive interpersonal relationships between women and health providers is important which include supportive care, building rapport, and using positive and clear language(Bohren et al., 2017). Experiences on care during birth were influenced by reception and respect, provision of information, technical skill, providers' behaviour, pain management and availability of nurses/midwives(Afaya et al., 2017). Health workers should be provided with support and supervision to build interpersonal skills, such as methods of effective communication, empathy, and providing emotional support. (Shakibazadeh et al., 2018)Therefore, the study aims to find out postnatal mothers' perception on care during labour.

\section{METHODOLOGY}

A descriptive cross-sectional design was used for the study in maternity ward of Tribhuwan University Teaching Hospital (TUTH). The total 294 postnatal mothers with normal vaginal delivery were recruited by using purposive sampling technique. Semi structured interview schedule and Likert scale were used. Ten percent postnatal mothers were taken for pretesting of the instrument in maternity ward of TUTH by excluding the study population.

Ethical approval for study was taken from the ethical review board of Research Department of Institute of Medicine. The permission to carry out the study was taken from concerned authority. The participants were assured for anonymity and confidentiality. No names 
ISSN: 2362-1303 (Paper) | eISSN: 2362-1311 (Online)

JOURNAL OF ADVANCED ACADEMIC RESEARCH (JAAR)

June 2021

or personal identification numbers were reflected on the questionnaires except the numbering for questionnaires, which was done for purposes of identification of data during data editing. After obtaining informed consent from each woman face to face interview was done to collect the data. The data from the completed questionnaires were cleaned, re-coded and entered into the computer using the statistical package for social sciences (SPSS) version 16.0 for analysis. Descriptive and inferential statistics were used to analyze the data.

\section{RESULTS}

Among 294 postnatal mothers; age group below 20 years were 8.2\%, 20 to 35 years were 90.8\%, and above 35 years were 1.0\%. Regarding the ethnicity; Brahmin/Chhetri were 60.2\%, Newar $10.9 \%$, Mongolian were $3.7 \%$, and others $25.2 \%$. Regarding religion; $85.7 \%$ were Hindu, $11.9 \%$ were Buddhist, $1.4 \%$ was Christian and $1 \%$ was Muslim. Regarding education; 37.4\% were Bachelors level and above, $22.8 \%$ were higher secondary (Intermediate) Level, $19.4 \%$ secondary level, $14.6 \%$ were primary level, $3.4 \%$ were illiterate and $2.4 \%$ were just literate. Likewise regarding occupation; $75.2 \%$ were homemakers, $14.6 \%$ were services holder, $3.7 \%$ were business and 1\% was agriculture. Regarding obstetrical characteristics; $93.9 \%$ were delivered between 2 to 15 hours, $5.1 \%$ were delivered about more than 15 hours and $1 \%$ were delivered within less than 2 hours. About parity, $60.9 \%$ were primiparous, $37.8 \%$ were multiparous and $1.4 \%$ were grand multiparous. Furthermore, regarding gestation; $89.5 \%$ were term and $10.5 \%$ were preterm. Likewise, $53.1 \%$ were male and $46.9 \%$ female child delivered.

Table 1: Care on Prevention of Infection and bladder care, Maintenance of Hydration, protection from Injury $(n=294)$

\begin{tabular}{|c|c|c|c|}
\hline Care related variables & Yes & No & N/A \\
\hline \multicolumn{4}{|l|}{ Prevention of Infection } \\
\hline Used clean and dry bed sheet & $255(86.73 \%)$ & $37(12.59 \%)$ & $2(0.68 \%)$ \\
\hline Clean bathroom, sink and floor & $189(64.29 \%)$ & $96(32.65 \%)$ & $9(3.06 \%)$ \\
\hline Use of clean bed pan & $180(61.22 \%)$ & $43(14.63 \%)$ & $71(24.15 \%)$ \\
\hline Mean & $208(70.75 \%)$ & $59(19.95 \%)$ & $27(9.3 \%)$ \\
\hline \multicolumn{4}{|l|}{ Bladder Care } \\
\hline $\begin{array}{l}\text { Encouraged to urinate after every } 1 \text { or } 2 \\
\text { hours }\end{array}$ & $213(72.45 \%)$ & $79(26.87 \%)$ & $2(0.68 \%)$ \\
\hline Assist to go toilet & $169(57.48 \%)$ & $82(27.89 \%)$ & $43(14.63 \%)$ \\
\hline Provide bed pan if unable to go toilet & $56(19.05 \%)$ & $84(28.57 \%)$ & $154(52.38 \%)$ \\
\hline Use of catheter to empty the bladder & $202(68.71 \%)$ & $17(5.78 \%)$ & $75(25.51 \%)$ \\
\hline mean & $160(54.42 \%)$ & $66(22.28 \%)$ & $69(23.3 \%)$ \\
\hline If catheter used $(n=202)$ & Frequency & Percent & \\
\hline Before child birth & 80 & 39.6 & \\
\hline
\end{tabular}


ISSN: 2362-1303 (Paper) | eISSN: 2362-1311 (Online)

JOURNAL OF ADVANCED ACADEMIC RESEARCH (JAAR)

June 2021

After child birth

Maintenance of Hydration

Encourage to drink nutritious fluid

Assist to drink fluid

Encourage to eat nutritious diet

Assist to eat food

Use of intravenous infusion

Mean

\section{Protection from Injury}

Never left alone during labour

Assist for ambulation

Assist for going toilet

Mean
122

60.4

$\begin{array}{lll}272(92.52 \%) & 20(6.8 \%) & 2(0.68 \%) \\ 240(81.63 \%) & 43(14.63 \%) & 11(3.74 \%) \\ 84(28.57 \%) & 202(68.71 \%) & 8(2.72 \%) \\ 58(19.73 \%) & 149(50.68 \%) & 87(29.59 \%) \\ 223(75.85 \%) & 62(21.09 \%) & 9(3.06 \%) \\ 175(59.66 \%) & 95(32.38 \%) & 23(7.96 \%)\end{array}$

Table 1 shows the perceived care related to infection prevention, bladder care, maintenance of hydration and protection from injury. About infection prevention; 86.73\% used clean and dry bed sheet; $64.29 \%$ said that bathroom, sink and floor was clean; and $61.22 \%$ used clean bedpan. In regard to bladder care; $72.45 \%$ were encouraged to urinate every 1 or 2 hours, $57.48 \%$ were helped to go to toilet for voiding, $19.05 \%$ were provided bedpan if unable toilet; $202(68.71 \%)$ were used catheter to empty the bladder. Out of 202 who used catheter to empty the bladder, $39.6 \%$ used before and $60.4 \%$ after childbirth. Likewise, care related to hydration maintenance; 92.52\% had encouraged to drink nutritious fluid as her wishes, $81.63 \%$ assisted to drink fluid, $28.57 \%$ encouraged to eat nutritious diet, $19.73 \%$ helped to have meal and $75.85 \%$ were given fluid through vein. Similarly, care related to injury prevention, $69.39 \%$ of postnatal mothers were never left alone during labour; $27.21 \%$ were helped in ambulation, and $55.1 \%$ were assisted to go toilet.

Table 2: Care Perception of Postnatal Mother on Comfort Measure and Pain Management, Informational Support, and Emotional Support during Labour $(n=294)$

\begin{tabular}{llll}
\hline Care of women & Yes & No & N/A \\
\hline Care on Comfort Measure & & & \\
position as per women's choice & $108(36.73 \%)$ & $179(60.88 \%)$ & $7(2.38 \%)$ \\
Teach for deep breathing during pain & $265(90.14 \%)$ & $27(9.18 \%)$ & $2(0.68 \%)$ \\
Encourage for deep breathing during pain & $264(89.8 \%)$ & $28(9.52 \%)$ & $2(0.68 \%)$ \\
Perform back massage during pain & $33(11.22 \%)$ & $255(86.73 \%)$ & $6(2.04 \%)$ \\
Use of cold sponge on forehead during pain & $13(4.42 \%)$ & $275(93.54 \%)$ & $5(1.7 \%)$ \\
Encourage for mobility & $66(22.45 \%)$ & $224(76.19 \%)$ & $4(1.36 \%)$
\end{tabular}


ISSN: 2362-1303 (Paper) | eISSN: 2362-1311 (Online) JOURNAL OF ADVANCED ACADEMIC RESEARCH (JAAR)

Encourage for position change

Assist for mobility

Assist for position change

Provide care by touching hand and body

Talk with women for diversional therapy

Mean

\section{Information about}

birthing area and their surrounding

rule and regulation of hospital

condition of the labour and child birth

Involve in treatment planning

Involve family in treatment planning

Inform about condition of the labour

Inform to family about condition of labour

Give information of queries about labour

Mean

\section{Emotional Support during Labour}

Woman have support person of her choice good communication

Discuss all procedures

Seek permission before doing any procedure

Discuss findings with woman

supportive, encouraging atmosphere for birth

Respect woman's wishes

Encourage privacy and confidentiality

Immediately fulfilled request

Showed quite, calm and confident behavior

Mean

$\begin{array}{lll}61(20.82 \%) & 203(69.28 \%) & 29(9.9 \%) \\ 79(26.87 \%) & 212(72.11 \%) & 3(1.02 \%) \\ 86(29.25 \%) & 177(60.2 \%) & 31(10.54 \%) \\ 78(26.53 \%) & 213(72.45 \%) & 3(1.02 \%) \\ 75(25.51 \%) & 217(73.81 \%) & 2(0.68 \%) \\ 103(34.88 \%) & 183(62.15 \%) & 9(2.91 \%)\end{array}$

$\begin{array}{lll}84(28.57 \%) & 209(71.09 \%) & 1(0.34 \%) \\ 135(45.92 \%) & 158(53.74 \%) & 1(0.34 \%) \\ 213(72.45 \%) & 80(27.21 \%) & 1(0.34 \%) \\ 248(84.35 \%) & 45(15.31 \%) & 1(0.34 \%) \\ 130(44.22 \%) & 161(54.76 \%) & 2(0.68 \%) \\ 271(92.18 \%) & 21(7.14 \%) & 2(0.68 \%) \\ 134(45.58 \%) & 155(52.72 \%) & 5(1.7 \%) \\ 223(75.85 \%) & 25(8.5 \%) & 46(15.65 \%) \\ 180(61.14 \%) & 107(36.31 \%) & 7(2.51 \%)\end{array}$

$\begin{array}{lll}159(54.08 \%) & 134(45.58 \%) & 1(0.34 \%) \\ 143(48.64 \%) & 148(50.34 \%) & 3(1.02 \%) \\ 149(50.68 \%) & 143(48.64 \%) & 2(0.68 \%) \\ 129(43.88 \%) & 163(55.44 \%) & 2(0.68 \%) \\ 249(84.69 \%) & 44(14.97 \%) & 1(0.34 \%) \\ 273(92.86 \%) & 19(6.46 \%) & 1(0.34 \%) \\ 238(80.95 \%) & 51(17.35 \%) & 5(1.7 \%) \\ 240(81.63 \%) & 52(17.69 \%) & 2(0.68 \%) \\ 217(73.81 \%) & 70(23.81 \%) & 7(2.38 \%) \\ 277(94.22 \%) & 16(5.44 \%) & 1(0.34 \%) \\ 207(70.54 \%) & 84(28.57 \%) & 3(0.85 \%)\end{array}$

Table 2 reveals the care perception of postnatal mother on comfort measure and pain management, informational support, and emotional support during labour. Regarding care about comfort measure and pain management; $36.73 \%$ were helped to maintain position as per women's choice, $90.14 \%$ ) were taught for deep breathing during pain, $89.8 \%$ were encouraged for deep breathing during pain, $11.22 \%$ were given back massage during pain, $4.24 \%$ were provided cold sponge on forehead during pain, $22.45 \%$ were encouraged for mobility, $20.82 \%$ 
ISSN: 2362-1303 (Paper) | eISSN: 2362-1311 (Online)

JOURNAL OF ADVANCED ACADEMIC RESEARCH (JAAR)

June 2021

were encouraged for position change, $26.87 \%$ were assisted for mobility, $29.25 \%$ were assisted for position change, $26.53 \%$ were provided care by touching hand and body, and $25.51 \%$ were talked with women for diversional therapy. Likewise, related to informational care;28.57\% got information about birthing area and their surroundings, $45.92 \%$ were informed about rule and regulation of hospital during admission, $72.45 \%$ were informed about the condition of the labour and childbirth, $84.35 \%$ were involved in treatment planning, $44.22 \%$ said to involve their family in treatment planning, $92.18 \%$ were informed about condition of the labour,45.58\% informed to family about the condition of the labour,75.85\% were given correct information of queries about labour. Similarly, in regard to emotional support during labour;54.08\% got support from person of their choice, $48.64 \%$ said service providers had good communication, $50.68 \%$ were discussed about all procedures, $43.88 \%$ were seeking permission before doing any procedure, $84.69 \%$ have discussed the findings of examinations and procedures, $92.86 \%$ were provided supportive, encouraging atmosphere for birth, $80.95 \%$ were respected their wishes, $81.63 \%$ were encouraged for privacy and confidentiality, $73.81 \%$ were immediately fulfilled their request, $94.22 \%$ were showed quite, calm and confident behaviour.

Table 3: Care immediately after child birth $(n=294)$

\begin{tabular}{llll}
\hline Care immediately after child birth & Yes & No & N/A \\
\hline $\begin{array}{l}\text { Measured BP immediately after delivery } \\
\text { Counsel to massage uterus for 2 hours of }\end{array}$ & $272(92.52 \%)$ & $22(7.48 \%)$ & $0(0 \%)$ \\
childbirth & & & \\
Encourage to pass urine within 2 hours of childbirth & $136(46.26 \%)$ & $156(53.06 \%)$ & $2(0.68 \%)$ \\
Help for breast feeding & $244(82.99 \%)$ & $20(6.8 \%)$ & $30(10.2 \%)$ \\
Advice to inform if 2 pads soaked within 2 hours & $177(60.2 \%)$ & $116(39.46 \%)$ & $1(0.34 \%)$ \\
Counsel about the pain on episiotomy repaired & $136(46.26 \%)$ & $134(45.58 \%)$ & $24(8.16 \%)$ \\
Mean & $201(68.31 \%)$ & $84(28.4 \%)$ & $10(3.23 \%)$ \\
\hline
\end{tabular}

Table 3 depicts the care of postnatal mother immediately after childbirth. In this regard;92.52\% were measured BP immediately after delivery, $81.91 \%$ were taught to massage the uterus for two hours after childbirth, 46.26\%) were taught to pass urine within two hours after childbirth, $82.99 \%$ were helped for breastfeeding, $60.2 \%$ were advised to inform if two pads soaked within two hours, $46.26 \%$ were informed about the pain on episiotomy repaired site.

Table 4: Level of perception of postnatal mother ( $n=294)$

\begin{tabular}{lll}
\hline Level of perception & Frequency & Percent \\
\hline$<3.00$ (negative) & 93 & 31.6 \\
$3.00+($ positive) & 201 & 68.4 \\
\hline Total & 294 & 100.0 \\
\hline
\end{tabular}


ISSN: 2362-1303 (Paper) | eISSN: 2362-1311 (Online)

JOURNAL OF ADVANCED ACADEMIC RESEARCH (JAAR)

June 2021

The perception level was calculated on the basis of mean score and was categorized as below 3 is negative perception, 3 and above is positive perception. This shows that most of the postnatal mothers201(68.4\%) had positive perception on care received during labour. And one third postnatal mothers $93(31.6 \%)$ were perceived care negatively during labour.

Table 5: Relationships among different support type and perception $(n=294)$

\begin{tabular}{|c|c|c|c|c|c|c|c|c|}
\hline Relationships & 1 & 2 & 3 & $\overline{4}$ & 5 & 6 & 7 & 8 \\
\hline overall perception & 1 & & & & & & & \\
\hline emotional support & $.444^{* *}$ & 1 & & & & & & \\
\hline infection prevention support & $.197^{* *}$ & $.175^{* *}$ & 1 & & & & & \\
\hline toileting support & $.145^{*}$ & $.143^{*}$ & $.465^{* *}$ & 1 & & & & \\
\hline maintenance of hydration & $.171^{* *}$ & $.159^{* *}$ & $.216^{* *}$ & $.430^{* *}$ & 1 & & & \\
\hline non injury support & $.319^{* *}$ & $.212^{* *}$ & $.338^{* *}$ & $.601^{* *}$ & $.365^{* *}$ & 1 & & \\
\hline pain relief/comfort support & $.501^{* *}$ & $.413^{* *}$ & .032 & .052 & $.145^{*}$ & $.310^{* *}$ & 1 & \\
\hline informational support & $.645^{* *}$ & $.456^{* *}$ & .097 & $.121^{*}$ & $.183^{* *}$ & $.179^{* *}$ & $.376^{* *}$ & 1 \\
\hline after delivery support & $.185^{* *}$ & $.262^{* *}$ & .022 & $.146^{*}$ & $.243^{* *}$ & .058 & $.184^{* *}$ & $.192^{* *}$ \\
\hline
\end{tabular}

**. Correlation is significant at the 0.01 level (2-tailed). Pearson Correlation

*. Correlation is significant at the 0.05 level (2-tailed). Pearson Correlation

In regard to the relationship among different support system and perception of postnatal mother regarding the care during labour; there was significant relationship among different support system (such as emotional support (44.44\%), infection prevention (19.7\%), support for bladder empty (14.5\%), maintenance of hydration (17.1\%), support for prevention of injury (31.9\%), support on pain relieve and comfort measures (50.1\%), informational support (64.5\%), and support after delivery (18.5\%)) and overall perception of care during labour.

\section{DISCUSSION}

Among 294 postnatal mothers; majority (90.8\%) were in 20 to 35 years' group, more than half (60.2\%) were Brahmin/Chhetri, majority (85.7\%) were Hindu, higher proportion $(37.4 \%)$ were with bachelors' level and above education, majority (75.2\%) were homemakers (housewife), and more than half $(53.1 \%$ ) were delivered male child. A descriptive study done in Egypt revealed 
ISSN: 2362-1303 (Paper) | eISSN: 2362-1311 (Online)

JOURNAL OF ADVANCED ACADEMIC RESEARCH (JAAR)

June 2021

that nearly half $(43 \%)$ of the postpartum women were from 30 to 40 years; about $41 \%$ have bachelor's degree; and majority (62.8\%) are housewives (Mousa \& Turingan, 2018).

Regarding the perception of care related to infection prevention; $86.73 \%$ used clean and dry bed sheet; $64.29 \%$ said that bathroom, sink and floor was clean; and $61.22 \%$ used clean bedpan. In regard to bladder care; $72.45 \%$ were encouraged to urinate in every 1 or 2 hours, $57.48 \%$ were helped to go to toilet for voiding, $19.05 \%$ were provided bedpan if unable to go to toilet; $202(68.71 \%)$ were used catheter to empty the bladder. Out of 202 who used catheter to empty the bladder, $39.6 \%$ used before and $60.4 \%$ after childbirth.

Likewise, perception of care related to hydration maintenance; $92.52 \%$ was encouraged to drink nutritious fluid as her wishes, $81.63 \%$ assisted to drink fluid, $28.57 \%$ encouraged to eat nutritious diet which is similar with the finding of a cross-sectional study of Portugal that is 27.4\%(Marques, 2017). Similarly, $19.73 \%$ helped to take meal and $75.85 \%$ had given fluid through vein that is nearly similar to finding of Portugal that is $80.6 \%$ (Marques, 2017).Furthermore, perception of care related to injury prevention; $69.39 \%$ were never left alone during labour; $27.21 \%$ were helped in ambulation, and $55.1 \%$ were assisted to go toilet.

In regard to perception of care on comfort measure and pain management; $36.73 \%$ were helped to maintain position as per women's choice, 90.14\%) were taught for deep breathing during pain, $89.8 \%$ were encouraged for deep breathing during pain, $11.22 \%$ were given back massage during pain, $4.24 \%$ were provided cold sponge on forehead during pain, $22.45 \%$ were encouraged for mobility. Likewise, $20.82 \%$ were encouraged for position change whereas a cross-sectional study was done in south Ethiopia depicts that $36.4 \%$ women were allowed to adopt the position of her choice to bear down (Gendisha, Id, Kondale, \& Id, 2019). Furthermore, $26.87 \%$ were assisted for mobility, $29.25 \%$ were assisted for position change, $26.53 \%$ were provided care by touching hand and body, and $25.51 \%$ were talked for diversional therapy.

Likewise, perception of care on informational care;28.57\% postnatal mothers were got information about birthing area and their surroundings, $45.92 \%$ were informed about rule and regulation of hospital during admission, $72.45 \%$ were informed about the condition of the labour and childbirth, $84.35 \%$ were involved in treatment planning, $44.22 \%$ said to involve their family in treatment planning. Similarly, 92.18\% were informed about condition of the labour which is similar to the study done in Kenya that is $91 \%$ (Kabo, Karani, Oyieke, Wakoli, \& Cheruiyot, 2016). About $45.58 \%$ postnatal mothers' family were informed about the condition of the labour. In this study $75.85 \%$ women were received correct information on their queries about labour which in contrast with the cross-sectional study done in south Ethiopia that is $20.3 \%$ were encouraged to ask about unclear points(Gendisha et al., 2019)..

Similarly, care perception regarding the emotional support during labour;54.08\% had got support from person of her choice. About $48.64 \%$ postnatal mothers said service providers had good communication whereas a cross-sectional retrospective study conducted in Egypt showed only 38.52\% (Mousa \& Turingan, 2018). Likewise, 50.68\% were discussed about all procedures and $43.88 \%$ were seeking permission before doing any procedure which is the contrast finding 
ISSN: 2362-1303 (Paper) | eISSN: 2362-1311 (Online)

JOURNAL OF ADVANCED ACADEMIC RESEARCH (JAAR)

June 2021

with cross sectional descriptive study done in Kenya which showed that most postnatal mother $(87.7 \%)$ were treated with respect, maintained privacy, taken consent prior the initiation of the procedure(Kabo et al., 2016). In this study care providers discussed the findings of examinations and procedures with $84.69 \%$ postnatal mothers which is contrast with study done in South Ethiopia that is 26\% only(Gendisha et al., 2019). Furthermore, 92.86\% were provided supportive, encouraging atmosphere for birth, $80.95 \%$ were respected their wishes, $81.63 \%$ were encouraged for privacy and confidentiality in this study which in contrast with the lancet report which showed $62.6 \%$ for privacy measure(Bohren et al., 2019). About $73.81 \%$ were immediately fulfilled their request. In this study among the postnatal mothers, $94.22 \%$ were perceived the quiet, calm and confident behaviour of care provider whereas $67 \%$ was found in the study done in South Africa (Maputle, 2018).

Regarding the care perception of postnatal mother immediately after childbirth;92.52\% were measured blood pressure immediately after delivery, $81.91 \%$ were taught to massage the uterus for two hours after childbirth, 46.26\%) were taught to pass urine within two hours after childbirth, $82.99 \%$ were helped for breastfeeding, $60.2 \%$ were advised to inform if two pads soaked within two hours, $46.26 \%$ were informed about the pain on episiotomy repaired site.

Regarding the care perception level which was calculated on the basis of mean score and was categorized as below 3 is negative perception, 3 and above is positive perception. This shows that most of the postnatal mothers 201(68.4\%) had positive perception on care received during labour and 93(31.6\%) were perceived care negatively during labour. A cross-sectional study done in Rwanda reveals nearly similar finding that is majority of women $(77.5 \%)$ had a good overall childbirth experience(Mukamurigo, Berg, Ntaganira, Nyirazinyoye, \& Dencker, 2017). But this is less than the finding from study done in Kenya that is $93.6 \%$ had a positive experience of quality in delivery care because they would recommend delivery services to friends or family in study site(Kabo et al., 2016).

In regard to the relationship among different support system and perception of postnatal mother regarding the care during labour. There is significant relationship among different support system (such as emotional support (44.44\%), infection prevention support (19.7\%), support for bladder empty (14.5\%), maintenance of hydration (17.1\%), support for prevention of injury $(31.9 \%)$, support on pain relieve and comfort measures $(50.1 \%)$, informational support $(64.5 \%)$, and support after delivery $(18.5 \%)$ ) and overall perception regarding care during labour.

\section{CONCLUSIONS}

There is significant relationship between different care received and perception of postnatal mother regarding the care during labour and overall perception of care during labour. Three fourth postnatal mother were perceived care positively and one third were perceived care negatively during labour. It indicates that the care during labour needs to be improved for best care perception. 
ISSN: 2362-1303 (Paper) | eISSN: 2362-1311 (Online)

JOURNAL OF ADVANCED ACADEMIC RESEARCH (JAAR)

June 2021

\section{ACKNOWLEDGEMENTS}

The authors would like to thank research department of Institute of Medicine, Tribhuvan University for research grant support and all postnatal mothers for their valuable response to this study.

Received: 24 May 2021

Accepted: 1 June 2021

Published: 22 June 2021

\section{REFRENCES}

Afaya, A., Yakong, V. N., Afaya, R. A., Salia, S. M., Adatara, P., \& Anthony, K. (2017). A Qualitative Study on Women's Experiences of Intrapartum Nursing Care at Tamale Teaching Hospital ( TTH ), Ghana. Tabriz University of Medical Sciences, 6(4), 303-314. https://doi.org/10.15171/jcs.2017.029

Bohren, M. A., Mehrtash, H., Fawole, B., Maung, T. M., Balde, M. D., Maya, E., ... Tunçalp, Ö. (2019). How women are treated during facility-based childbirth in four countries: a crosssectional study with labour observations and community-based surveys. The Lancet, 394(10210), 1750-1763. https://doi.org/10.1016/S0140-6736(19)31992-0

Bohren, M. A., Titiloye, M. A., Kyaddondo, D., Hunter, E. C., Oladapo, O. T., Tunçalp, Ö., ... Mugerwa, K. (2017). Defining quality of care during childbirth from the perspectives of Nigerian and Ugandan women: A qualitative study. International Journal of Gynecology and Obstetrics, 139(December), 4-16. https://doi.org/10.1002/ijgo.12378

Gebremichael, M. W., Worku, A., Medhanyie, A. A., \& Edin, K. (2018). Women suffer more from disrespectful and abusive care than from the labour pain itself: a qualitative study from Women' s perspective, 1-6.

Gendisha, G., Id, U., Kondale, M., \& Id, G. (2019). Disrespect and abuse of women during childbirth in public health facilities in Arba Minch town, south Ethiopia - a cross-sectional study, 1-17.

Kabo, J., Karani, A., Oyieke, J., Wakoli, A. B., \& Cheruiyot, B. (2016). Experiences in Care Given During Child Birth at a Referral Hospital in Kenya. Global Journal of Biology and Health Sciences, 5(January), 38-42. Retrieved from http://ecommons.aku.edu/eastafrica_fhs_sonam/118

Lunda, P., Minnie, C. S., \& Benadé, P. (2018). Women's experiences of continuous support during childbirth: A meta-synthesis. BMC Pregnancy and Childbirth, 18(1), 1-11. https://doi.org/10.1186/s12884-018-1755-8

Maputle, M. S. (2018). Support provided by midwives to women during labour in a public hospital, Limpopo Province, South Africa: A participant observation study. BMC Pregnancy and Childbirth, 18(1), 1-11. https://doi.org/10.1186/s12884-018-1860-8

Marques, M. (2017). Perception of be Cared in Childbirth at the Light of the WHO Model. 
ISSN: 2362-1303 (Paper) | eISSN: 2362-1311 (Online)

JOURNAL OF ADVANCED ACADEMIC RESEARCH (JAAR)

American Journal of Nursing Science, 6(6), 478.

https://doi.org/10.11648/j.ajns.20170606.15

Mousa, O., \& Turingan, O. M. (2018). Quality of care in the delivery room: Focusing on respectful maternal care practices. Journal of Nursing Education and Practice, 9(1), 1. https://doi.org/10.5430/jnep.v9n1p1

Mukamurigo, J. U., Berg, M., Ntaganira, J., Nyirazinyoye, L., \& Dencker, A. (2017).

Associations between perceptions of care and women's childbirth experience: A populationbased cross-sectional study in Rwanda. BMC Pregnancy and Childbirth, 17(1), 1-7. https://doi.org/10.1186/s12884-017-1363-z

Namujju, J., Muhindo, R., Mselle, L. T., Waiswa, P., Nankumbi, J., \& Muwanguzi, P. (2018). Childbirth experiences and their derived meaning : a qualitative study among postnatal mothers in Mbale regional referral hospital , Uganda, 1-11.

Shakibazadeh, E., Namadian, M., Bohren, M. A., Vogel, J. P., Rashidian, A., \& Pileggi, V. N. (2018). Respectful care during childbirth in health facilities globally : a qualitative evidence synthesis. https://doi.org/10.1111/1471-0528.15015 